\title{
Measurement of velocities in gas-liquid two-phase flow using Laser Doppler Velocimetry
}

Sep 1992

Knolls Atomic Power Lab., Schenectady, NY (United States)

Reproduced and Distributed by:

U.S. DEPARTMENT OF ENERGY

Office of Scientific and Technical Information

P.O. Box 62

Oak Ridge, TN 37831 
$$
\text { . }
$$ 


\section{DISCLAIMER}

This report was prepared as an account of work sponsored by an agency of the United States Government. Neither the United States Government nor any agency Thereof, nor any of their employees, makes any warranty, express or implied, or assumes any legal liability or responsibility for the accuracy, completeness, or usefulness of any information, apparatus, product, or process disclosed, or represents that its use would not infringe privately owned rights. Reference herein to any specific commercial product, process, or service by trade name, trademark, manufacturer, or otherwise does not necessarily constitute or imply its endorsement, recommendation, or favoring by the United States Government or any agency thereof. The views and opinions of authors expressed herein do not necessarily state or reflect those of the United States Government or any agency thereof. 


\section{DISCLAIMER}

Portions of this document may be illegible in electronic image products. Images are produced from the best available original document. 
KAPL --4738

DE93 008083

\title{
Measurement of Velocities in Gas-Liquid Two-Phase Flow Using Laser Doppler Velocimetry
}

P.F. Vassallo, T.A. Trabold,

W.E. Moore, and G.J. Kirouac

\author{
Prepared for \\ The United States Department of Energy \\ Assistant Secretary for Nuclear Energy \\ Deputy Assistant Secretary for Naval Reactors
}

\author{
Prepared by \\ General Electric Company \\ KNOLLS ATOMIC POWER LABORATORY \\ Schenectady, New York
}

Contract No. DE-AC12-76-SN00052

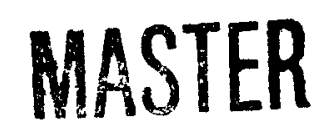




\section{DISCLAIMER}

This report was prepared as an account of work sponsored by an agency of the United States Government. Neither the United States Government nor any agency thereof, nor any of their employees, makes any warranty, express or implied, or assumes any legal liability or responsibility for the accuracy, completeness, or usefulness of any information, apparatus, product, or process disclosed, or represents that its use would not infringe privately owned rights. Reference herein to any specific commercial product, process, or service by trade name, trademark, manufacturer, or otherwise, does not necessarily constitute or imply its endorsement, recommendation, or favoring by the United States Government or any agency thereof. The views and opinions of authors expressed here in do not necessarily state or reflect those of the United States Government or any agency thereof. 


\section{CONTENTS}

Page

ABSTRACT $\ldots \ldots \ldots \ldots \ldots \ldots \ldots \ldots \ldots \ldots \ldots \ldots \ldots \ldots \ldots \ldots \ldots \ldots \ldots \ldots \ldots$

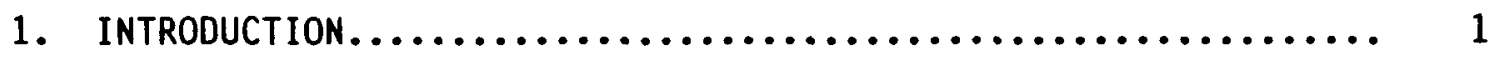

2. EXPERIMENTAL APPARATUS AND TEST PROCEDURE.............. 4

3. RESULTS AND DISCUSSION........................ 7

3.1 Validation of LDV Technique................. 7

3.2 Phase Velocity Measurements for Various

Flow Regimes.......................... 9

4. CONCLUSIONS................................. 11

REFERENCES................................ 11

TABLES

Table

1 Summary of Selected Studies: LDV Measurements

in Gas-Liquid Two-Phase Flows.................. 16 


\section{ILLUSTRATIONS}

Figure

Page

1 Laser Beam Crossing and Ellipsodial LDV

Measurement Volume......................... 18

2 Retro-Reflector and Lens with Standard LDV

Probe..................................... 19

$3 \quad$ Experimental Set-Up......................... 20

4 Bubble Velocity Comparison, No Liquid Flow........... 21

$5 \quad$ Liquid Velocity Profiles, No Gas Flow.............. 22

6 Data Rate Response at Constant Gain............... 23

7 Two-Phase Velocity Measurements, No Liquid Flow....... 24

8 Two-Phase Velocity Measurements, $\mathrm{QI}=300 \mathrm{ml} / \mathrm{min} . \ldots . . .25$

9 Two-Phase Velocity Measurements, $\mathrm{QL}=600 \mathrm{ml} / \mathrm{min} . \ldots . .26$

10 Two-Phase Velocity Measurements, $Q I=900 \mathrm{ml} / \mathrm{min} . . . . .27$

11 Void Fraction as a Function of Gas Flow............ 28

Plate

1 Two-Phase Flow Regimes for $Q_{1}=0 / \mathrm{ml} / \mathrm{min} . \ldots \ldots \ldots \ldots$ 


\begin{abstract}
Measurements of bubble and liquid velocities in two-phase flow have been made using a new forward/backward scattering Laser Doppler Velocimetry (LDV) technique. This work was performed in a 6.4 by $11.1 \mathrm{~mm}$ vertical duct using known air/water mixtures. A standard LDV fiber optic probe was used to measure the bubble velocity, using direct backscattered light. A nove 1 retro-reflector and lens assembly permitted the same probe to measure the liquid velocity with direct forwardscattered light. The bubble velocity was confirmed by independent measurements with a high-speed video system. The liquid velocity was confirmed by demonstrating the dominance of the liquid seed data rate in the forward-scatter measurement. Experimental data are presented to demonstrate the accuracy of the technique for a wide range of flow conditions, from bubbles as small as $0.75-m m-d i a m$ to slugs as large as 10$\mathrm{mm}$ wide by $30-\mathrm{mm}$ long. In the slug regime, the LDV technique performed velocity measurements for both phases, for void fractions up to $50 \%$, which was the upper limit of our experimental investigation.
\end{abstract}





\title{
Measurement of Velocities in Gas-Liquid Two-Phase Flow Using Laser Doppler Velocimetry
}

\author{
P.F. Vassallo, T.A. Trabold, \\ W.E. Moore, and G.J. Kirouac
}

\section{INTRODUCTION}

A currently active area of development in gas-liquid two-phase-flow predictive methods is the two-fluid model, in which separate conservation equations are written for each phase. While it is generally recognized that this model is sufficiently rigorous for the calculation of detailed flow characteristics, its application is dependent on empirically derived constitutive relations that describe phase interactions. The local liquid and vapor phase velocities are two of the most important parameters that need to be measured.

Laser Doppler velocimetry (LDV) has been utilized extensively for the measurement of velocities in single phase flows, and complete details of its theoretical and experimental development are available in several standard references (e.g., Durst et al., 1976). Briefly, when two laser beams cross at a point in space, an interference fringe pattern, characterized by alternating bright and dark regions, is formed within an ellipsoidal measurement volume (Figure 1 ). The size of this ellipsoid is dependent on the laser beam diameter and beam crossing angle. As a particle passes through the measurement volume, light is scattered in various directions. The Doppler shift frequency of scattered light $\left(f_{D}\right)$ is related to the particle velocity $\left(V_{p}\right)$ by the equation

$$
f_{D}=\frac{2 v_{\rho} \operatorname{sink}}{\lambda}
$$

where $K$ is half the included angle between the incident laser beams and $\lambda$ is the associated laser light wavelength. The component of the velocity vector measured lies in the plane of the beams and is perpendicular to the bisector of the beam crossing angle. Natural contaminants existing within the fluid, or "seed" particles added to enhance the LDV measurement, are small enough so that their velocity is considered equivalent to the local fluid velocity.

In principle, Equation (1) should be equally applicable for cases in which more than one phase is present, even if the scattering particles or bubbles are larger than the measurement volume (Durst and Zarè, 1975). The difficulty associated with applying the LDV technique to 
experiments involving gas-1iquid two-phase flows can be attributed to differences in light scattering characteristics between relatively small seed particles in the continuous liquid phase and larger transparent bubbles which comprise the dispersed gas phase. A number of theoretical studies have been performed to determine how light is scattered from various types of particles. Extrapolation of these theories to actual experimental two-phase-flow situations is, however, complicated by factors such as particle/bubble nonsphericity and multiple scattering from bubble interfaces. It was understood from the outset that optimization of the LDV optical configuration for the present experiments could not be obtained by purely theoretical means. Rather, the initial step in our LDV development program was to review the literature, focussing on two-phase flow applications. In so doing, valuable insight was gained in determining how the LDV technique can best be applied to experiments involving mixed gas-liquid duct flows.

Since laser Doppler velocimetry techniques were introduced nearly thirty years ago, well over 1000 papers have been published on the subject (Adrian, 1983). However, only a few of these studies have directly addressed experimental applications of LDV in gas-liquid two-phase flows in which the gas is the dispersed phase. A summary of publications dealing with LDV measurements in dispersed gas-liquid flows is provided in Table 1.* Although several authors have attempted to measure both liquid and gas velocities ( $V_{1}$ and $V_{g}$, respectively) in two-phase systems, this has been done in only a few cases for pipe or duct flows and no results were found for thin channels. Also, almost all studies have been limited to low void fractions ( $\alpha \leq 30 \%)$.

The use of LDV in gas-liquid flows is difficult compared with experiments in single phase flows. This is due to the complicated light scattering behavior of such systems, which leads to two primary experimental problems:

- As the concentration of gas-liquid interfaces increases, the incident laser light is increasingly scattered, so an LDV measurement volume can only be formed for very short time periods. This problem becomes more pronounced with increasing void fraction and/or test section fluid thickness.

$\star \bar{A}$ number of papers dealing with single bubble streams rising in quiescent liquid, notbly those by Martin and co-workers (Martin et al., 1981; Lisk et al., 1982; Martin and Chandler, 1982; Brankovic et a1., 1984a; 1984b) and Durst and co-workers (Durst et a1., 1986) are not included in Table 1. 
- When a Doppler-shifted event occurs in the measurement volume, the scattered light transmission path and the optical and data acquisition configuration must be such that LDV signals due to bubbles and seed particles can be detected and separately analyzed.

Several authors have investigated the range of void fractions for which LDV measurements can be made. For their extensive tests in a re1atively large 450-mm square duct, Marié and co-workers (Marié et al., 1982; Marie, 1983; Marie and Lance, 1983) concluded that LDV measurements could be made up to a void fraction of $10 \%$. Boerner et a1. (1984) performed a study in which the two-phase-flow field thickness could be varied. Their results indicated a void fraction limit of about $23 \%$ for liquid phase LDV measurements in a 9.5-mm test section. This finding is roughly consistent with the work of Ohba et a). (1976; 1977a; 1977b) who were able to perform LDV experiments in an 11-mm square duct up to $\alpha \sim 30 \%$. For the case of an air jet discharged into water flowing vertically through a 100-mm square duct, Grainer et a1. (1984) acquired liquid velocity data using LDV up to a mean void fractions of $20 \%$. However, data were also obtained near the exit of the $1.5-\mathrm{mm}$ air nozzle in regions where the local void fraction was as high as 70\%. Davies (1973) and Davies and Unger (1973) ran both air/water and steam/water pipe flow tests, but provided little data to support their conclusions. Sheng and Irons (1991) carried out experiments up to $a=50 \%$ for air bubbles rising in water, but both phase velocities could be obtained using LDV only up to void fractions of $40 \%$. Wilson and co-workers (Wilson, 1982; Wolf et a1., 1983) performed tests at void fractions up to about $80 \%$ in air/water flows. Their method of extracting the slip ratio (i.e., $v_{g} / V_{p}$ ) from the velocity probability density distribution may not be valid for $\leq 30 \%$. However, their extensive results clearly indicate the feasibility of the LDV technique for moderate to high void fractions. As a whole, these publications provided ample evidence that LOV measurements can be made over a wide void fraction range, provided the optical path length through the bubbly flow is not too long.

The problem of how to discriminate the liquid and vapor phase ve1ocities was reported in only three studies for gas-liquid pipe or duct flows (Neti and Cole11a, 1983; Brankovic et al., 1986; Ohba et al., 1986). Brankovic et al. employed a single detector in the forwardscattering (0-deg) direction. Signals due to liquid seed particles and bubbles were separated, using amplitude discrimination of the Doppler bursts. The threshold voltage, which unambiguously admitted Doppler bursts from bubbles at a high rate, was three times that for the liquid measurement. An alternative technique, reported in the other two publications, is to use multiple detectors. The liquid seed particles were measured in the forward-scattering direction, while bubbles were mea- 
sured at off-axis forward scattering angles, at $90 \mathrm{deg}$, or the backscattering (180-deg) direction. Bubbles will still be measured by the forward scattering detector if amplitude discrimination is not used. In many applications, however, the frequency with which bubbles pass through the measurement volume is low enough so that the ir contribution can be considered to have an insignificant effect on the liquid velocity probability distribution measurement.

It is concluded from this review that it is possible to obtain measurements of both phase velocities in gas/liquid flows using laser Doppler velocimetry. However, for a given test section geometry, a practical void fraction limit exists above which it is not possible to obtain reliable measurements. The purpose of the present paper is to report on the deve lopment of an LDV direct forward/backward scattering technique capable of measuring $V_{1}$ and $V_{g}$ in two-phase flows through a narrow rectangular duct over a wide range of void fraction. In Section 2, a novel optical method is described that permits both bubble and liquid velocity measurements to be made using only one fiber optic LDV probe. The results of experiments performed with various gas and liquid flow rates and two-phase flow regimes are discussed later, in Section 3.

\section{EXPERIMENTAL APPARATUS AND TEST PROCEDURE}

In a standard backscatter LDV probe, a lens at the end of the probe focuses the laser beams to form the measurement volume within the test section. As a particle or bubble passes through this volume, it scatters light in all directions. The intensity of the scattered light increases with particle size and relative index of refraction, and may be two to three orders of magnitude greater in the forward direction than in the backward direction for small particles (Fingerson et al., 1990). A detection lens inside the probe picks up the backscattered light. For micron-sized seed particles, this light is generally too weak to be detected. However, the larger sized bubbles can be detected using backscattered light. This permits the bubble velocity to be measured with the standard backscatter probe.

To measure the liquid velocity, it is necessary to utilize the relatively intense forward-scattered light. One way to detect this light would be to place another detector across from the transmitting probe on the opposite side of the test section. However, this would require an additional probe, increasing expense and optical alignment complexity. The method adopted here uses a retro-reflector and lens combination to reflect the forward-scattered light back toward the probe, focusing it at the measurement volume. This light is then detected by a standard backscatter probe, as shown in Figure 2. The focal length of the transmitting lens defines the position of the measurement volume. A seed 
particle passing through this volume scatters light in the direction of lens R. This lens is positioned exactly one focal length away from the measurement volume, causing light rays within the cone to leave the lens as parallel rays of light. The retro-reflector is a prism that reflects light parallel to the incoming path. Lens $R$ then focuses the light back at the measurement volume, where it is collected by the detection lens located in the probe. This procedure uses the standard backscatter probe as a forward-scatter light detector, without any modification of the probe.

The two phases are now easily discriminated by interupting the forward-scattering light path. Blocking the light path to the retroreflector permits only backscatter light to be detected; this defines the vapor phase velocity. Uncovering the retro-reflector allows both back and forward-scatter light to be detected, but the forward-scatter light is much more intense, making the backscattered light negligible. Because micron-sized particles are present in numbers greatly exceeding the bubble density, the forward-scattered light defines the liquid velocity.

The objective of the current experiments was to develop a practical LDV system for use in a high-pressure steam/water test section in which the optical access is restricted to straight forward/backward light scattering. To demonstrate the technique, the test section and associated apparatus were both kept relatively simple (see Figure 3 ). The test section was $44.5 \mathrm{~mm}$ high and 6.4 by $11.1 \mathrm{~mm}$ in cross section, made by epoxying glass microscope slides to an aluminum frame. The working fluid was water, and experiments were performed both with and without the addition of 5- $\mathrm{m}$ polystyrene seed particles. Flexible rubber tubing connected the test section to a liquid peristaltic pump. This pump, calibrated with a graduated cylinder and stopwatch, provided a liquid volumetric flow rate $\left(Q_{1}\right)$ between 0 and $1000 \mathrm{ml} / \mathrm{min}$. A second peristaltic pump, calibrated with a Gilmont flowmeter, was used to provide the gas flow. The range of flow rates $\left(Q_{g}\right)$ for the gas pump was 0 to $970 \mathrm{ml} / \mathrm{min}$ at standard temperature and pressure. Two hypodermic needles, $1.6 \mathrm{~mm}$ in diameter, were inserted in the rubber tubing just below the test section, to inject the air directly into the liquid flow. The two-phase flow exiting the test section was channeled upward into a simple void fraction measurement device. This consisted of a 12.7-mm-diam graduated cylinder, $356 \mathrm{~mm}$ long, with a quick-action valve at either end, connected with a common handle. Rapid valve closure trapped the two-phase mixture, and, after the air rose to the top, an average void fraction could be determined.

The LDV fiber optic probe used in these experiments (TSI Model 9279-1) has a focal length of $102 \mathrm{~mm}$ and a beam spacing of $15 \mathrm{~mm}$, pro- 
ducing a measurement volume $2.1 \mathrm{~mm}$ long and $0.12 \mathrm{~mm}$ wide. A mask was placed over the end of the probe to prevent reflections off the test section walls from entering the probe. The mask had holes just large enough for the primary beams, and a 7.9- $\mathrm{mm}$ hole in the center to accept the scattered light. Standard optical components were used to form two green and two blue beams from a $4 \mathrm{~W}$ argon-ion laser (Coherent Innova $300)$ and guide them into the probe. For each color, a Bragg shift module was used to impart a frequency shift to one of the beams, allowing zero and negative velocities to be measured as well as positive velocities. The blue or green signals detected by the probe were analyzed with two TSI $1990 \mathrm{C}$ signal processors, operated in the cont inuous and random mode.

All the optical components, including the probe and retro-reflector were mounted on an optical table. This table could be moved in three orthogonal directions with an accuracy of $0.01 \mathrm{~mm}$. The test section was held fixed on a separate table, allowing free movement of the measurement volume with respect to the test section. The lens and retroreflector assembly were positioned on a rail aligned with the axis of the probe. The assembly could be moved along this rail to accurately match the position of the lens to the focal length. The lens was planoconvex, with a focal length of $75 \mathrm{~mm}$; the retro-reflector was a $12.7-\mathrm{mm}$ prism. The optimum position of the lens and retro-reflector was determined by maximizing the data rate observed on the signal processor.

The center of the test section was located by moving the optical table until flare was observed at both walls, and then moving halfway between. Except for the measurements of velocity profiles, all other measurements were taken at this central plane, approximately halfway up the test section. Since the flow under investigation was vertical, only this component of velocity was measured. The vapor and liquid flow rates were set to establish the flow conditions for any given measurement. To measure the vapor velocity, the retro-reflector was blocked, and the gain was lowered until the data rate corresponded to between 4 and $10 \mathrm{cps} ; 2500$ total samples were taken for each measurement. Using low gain assured detection of bubble signals only, and avoided the detection of the smaller seed signals. The liquid velocity was determined by uncovering the retro-reflector, and taking a measurement in forward scatter. Since the data rate is much higher in this configuration, more data samples were taken. Four measurements of 2500 samples each were acquired, and averaged to obtain the liquid velocity. While the velocity measurements were under way, a NAC-400 high-speed video system (HSV) was used to record the flow field. These recordings were used to identify the flow regimes and to independently measure the velocity of the bubbles rising in the channel. The HSV was operated at 200 frames/sec, with an image magnification of 5 . 


\section{RESULTS AND DISCUSSION}

\subsection{Validation of LDV Technique}

To confirm the vapor velocity measurements, the gas volume flow was varied from 50 to $970 \mathrm{ml} / \mathrm{min}$ with no external liquid flow, and HSV and LDV backscatter measurements were taken at each flow condition. Figure 4 shows the results; the error bars in the figure correspond to the estimated accuracy of the HSV bubble velocity measurments. These measurements were difficult for several reasons: (1) the velocity was measured over a finite distance on the HSV monitor $(25 \mathrm{~mm}$ centered about the measurement volume), while the LDV measured the velocity at a point, (2) interpretation of bubble position became harder to define as the bubbles became larger, deformed, and obscured each other, (3) only 10 to 20 bubbles were visually tracked to provide a mean velocity on the HSV, compared with 2500 for the LDV, and (4) the bubble velocity from the HSV was averaged over just a few seconds, while the LDV averaged the bubble velocity between 5 and 10 minutes. All these factors lead to an estimated accuracy of $\pm 10 \%$ on the HSV bubble velocity measurements, as indicated by the error bars in Figure 4. The results compare we 11, indicating that the LDV backscatter measurement has been correctly identified as the gas phase velocity.

The liquid velocity measurements were harder to confirm because no independent technique was available to measure the liquid velocity in two-phase flow. However, the accuracy was confirmed for single-phase liquid flow, within this test section. It was also shown, via data rate comparisons, that for two-phase flow the LDV forward scattering technique must be sensing primarily the seed, and therefore measuring the liquid velocity. The following discussion explains these points in detail.

The liquid velocity in single-phase flow was confirmed by pumping a known volume flow rate through the test section, measuring the velocity profile across the test section, integrating the profile over the test section cross sectional area, and comparing the integrated result with the known volume flow rate. Because the measurement volume is $2.1 \mathrm{~mm}$ long, the velocity profile in the narrow $(6.35 \mathrm{~mm})$ test section direction could not be measured easily. However, the measurement volume is only $0.12 \mathrm{~mm}$ wide, permitting detailed measurements of the profile in the transverse $(11.1 \mathrm{~mm})$ direction. The profile near the glass walls in the thickness direction was then assumed to be the same as the transverse profile. Figure 5 shows the measured velocity profile across the test section for two different flow rates. Both profiles are relatively flat, and both have a slight peak located near the right wall. The profiles are relatively flat because the flow is still developing; they have a 
peak near the right wall because the flow is turning slightly as it enters the test section. Neither of these points affects the analysis presented below.

In the thickness direction, the velocity profile was assumed to have the form:

$$
v=v_{\max }\left(\frac{x}{r}\right)^{\frac{1}{n}}
$$

Here $n$ is the profile exponent, and $v_{\max }$ is the maximum velocity in the center of the duct (i.e., at $x=r$ ). From the data points near the wall in Figure 6, a proper exponent for both flow rates was determined. These were $n=4$ and $n=7$ for the low and high flow, respectively. The integra 1

$$
Q=\int_{0}^{1} 2\left(\int_{0}^{r} V(x, y) d x\right) d y
$$

represents the volume flow rate of the fluid passing through the test section, where 1 is the extent in the transverse $(y)$ direction and $2 r$ is the extent in the thickness $(x)$ direction. Using trapezoidal integration in the $y$ direction, we obtain:

$Q=\left[\int_{0}^{r} v_{\max }\left(\frac{x}{r}\right)^{\frac{1}{n}} d x+\int_{0}^{r} v_{\max }\left(\frac{x}{r}\right)^{\frac{1}{n}} d x\right] \Delta y+\left[2 \int_{0}^{r} \sum_{1=2}^{m-1} v_{\max }\left(\frac{x}{r}\right)^{\frac{1}{n}} d x\right] \Delta y$

where $m$ is the number of data points taken across the transverse direction. This procedure yielded $Q=204$ and $798 \mathrm{ml} / \mathrm{min}$ for the high and low flow rate cases. These values are within $\pm 10 \%$ of the known volumetric flows provided by the calibrated pump. Therefore, the LDV probe, using forward-scatter data, correctly identifies the liquid velocity for single phase liquid flow within this test section.

Data rate comparisons are used to show that the forward-scatter arrangement is measuring primarily the liquid velocity, even in twophase flow. Figure 6 shows a $\log$ plot of the data rate as a function of vapor volume flow rate, for both backscatter and forward-scatter configurations. The gain was held constant throughout. Notice that the forward-scatter data rate decreases with increasing gas flow. This is because the bubbles displace the liquid, and, therefore, reduce the amount of seed detected. Also notice the difference in magnitude between the data rate in forward scatter and backscatter. Because the backscatter data rate is indicative of the actual rate of bubbles 
scattering light from the measurement volume (on the order of $10 \mathrm{~Hz}$ as observed on the HSV), the ratio of the backscatter rate to the forwardscatter rate gives the percentage of bubbles measured among the liquid seed. Based on the data in Figure 6 , even without seed addition, this is a relatively low percentage. At the highest gas flow, the ratio is under $4 \%$; at the lowest flow, it is only $0.1 \%$. Whenever this percentage needs to be reduced, additional seed may be added. Adding seed to the loop produced an obvious increase in the forward-scatter data rate, without affecting the backscatter rate. Now the percentage of bubbles measured along with the seed is always under $2 \%$, implying that the forward-scatter arrangement provides a reliable measure of the liquid velocity.

\subsection{Phase Velocity Measurements for Various Flow Regimes}

Having validated the direct forward/backward scattering technique for two-phase measurements, velocity results are now presented for a range of flow regimes. Figure 7 shows the results for the case of zero net liquid flow, and varying gas flows. The regimes in the figure were based on observations using the HSV and still pictures. At gas flow rates below $150 \mathrm{ml} / \mathrm{min}$, the bubbly region was observed. Plate la shows a picture of the bubbles in this regime, for $Q_{g}=50 \mathrm{ml} / \mathrm{min}$. The bubbles pictured are elliptical in shape, with an equivalent spherical diameter of $\sim 3 \mathrm{~mm}$. As the vapor flow rate increases, the bubbles become larger, but they are relatively uniform until the gas flow rate increases to $150 \mathrm{ml} / \mathrm{min}$. At this flow rate, some much larger gas bubbles can be seen that nearly fill the channel width. This is the bubbly-slug regime, an example of which is shown in Plate $1 \mathrm{~b}$ for $Q_{g}=350 \mathrm{ml} / \mathrm{min}$. At higher gas flows, between 400 and $850 \mathrm{ml} / \mathrm{min}$, the larger bubbles become more prominent, forming definite vapor slugs which fill the entire width of the test section. These slugs are followed by smaller bubbles within the liquid. As the gas flow increases, the length of the slugs becomes longer, until at flows over $Q_{g}=850 \mathrm{ml} / \mathrm{min}$, the slugs are long enough, at times, to fill the entire test section. This is the transition regime, sometimes approximating annular flow, but still containing smaller bubbles within intermediate liquid sections. Plates $1 \mathrm{c}$ and $1 \mathrm{~d}$ show examples of the slug and transition regimes.

Two-phase velocity measurements were taken throughout these regimes, as demonstrated in Figure 7. The dip in the bubble velocity is explained by considering how the bubbles interact within the confines of the test section. At the lowest gas flow rate, the 3-mm-diam bubbles are relatively far apart, and rise with little impedance. As the gas flow rate increases, the bubbles begin to collide with the test section walls and also with each other, causing their velocity to decrease. Eventually the 
gas flow rate becomes high enough to overcome this drag effect, and the bubble velocity starts to rise. This is seen to occur near $Q_{g}=300$ $\mathrm{ml} / \mathrm{min}$, after which the bubble velocity increases steadily with further increase in the gas flow rate.

The liquid velocity increases monotonically with increasing air flow rate. Because there is no external liquid flow, the liquid velocity is induced only by the rising bubbles. Therefore, the pumping action of the bubbles increases as the gas flow increases, and the liquid velocity rises continual1y. Notice how the relative velocity $\left(V_{g}-V_{p}\right)$ changes as a function of gas flow rate. The relative velocity is highest at the lowest gas flow rates, and decreases until $Q_{g}=550 \mathrm{ml} / \mathrm{min}$, beyond which it becomes approximately constant. At $Q_{g}=550 \mathrm{ml} / \mathrm{min}$ and higher, the slugs in the test section drive the flow at a constant relative rate. The faster the slug, the faster the liquid moves behind it, maintaining, however, the same relative speed.

Figures 8 through 10 present the velocity results in the center of the test section for three separate liquid flow rates. Comparing these figures with figure 7 reveals some important differences. As the liquid flow rate increases, the bubble and liquid velocities increase, the boundaries of the flow regimes shift to higher gas flows, and the dip in bubble velocity becomes less pronounced until it disappears entirely in Figure 10. The increase in bubble and liquid velocity is a direct result of the higher liquid flow. The flow regimes shift because at higher liquid flaws, it becomes more difficult for slugs to form, and the bubble regimes become more prominent. Indeed, at the highest liquid flow $\left(Q_{1}=900 \mathrm{ml} / \mathrm{min}\right)$, slugs are not observed at all, and the only regimes present are bubbly and bubbly-slug. The dip in bubble velocity is less apparent at higher liquid flows, because the bubbles are smaller and less likely to collide with the walls. For example, the average bubble size in Figure 7 at $Q_{g}=50 \mathrm{ml} / \mathrm{min}$ is $3 \mathrm{~mm}$, while in Figure 10 it is only $1.5 \mathrm{~mm}$. Therefore, when the bubble size increases in Figure 10 , they do not suffer as much wall drag as they do in Figure 7, and instead of slowing down they speed up due to buoyancy.

The average void fraction was measured with two quick-action valves and a graduated cylinder, as discussed in Section 2. Because the cross sectional area and geometry of the cylinder are different than the test section, the void fraction in the cylinder is not exactly the same as in the test section. However, it is possible to relate the void fraction in the test section to the measurement in the cylinder. The ZuberFindlay drift flux model (Zuber and Findlay, 1965) was used for this analysis. The void fraction in the test section was found to be 4 to $10 \%$ higher than its corresponding value in the measuring cylinder. Figure 11 presents the average void fraction in the test section as a 
function of gas flow rate. The void fraction increases with increasing gas flow, and decreasing liquid flow. The maximum void fraction attainable occurs at $Q_{g}=970 \mathrm{ml} / \mathrm{min}$ with $Q_{j}=300 \mathrm{ml} / \mathrm{min}$, and is $\sim 50 \%$. Note, this is an average void fraction. The local void fraction where the velocity measurements are taken, i.e., in the center of the test section, would be somewhat higher than this. We were unable to measure the void fraction for zero liquid flow because the valve-andcylinder method requires some liquid flow to be accurate.

\section{CONCLUSIONS}

Previous work reported in the open literature indicated the potential for measuring velocities in gas/liquid two-phase flow experiments using Laser Doppler Velocimetry. In the present work, a single backscatter LDV probe and retro-reflector device were used to measure both the liquid and gas phase velocities in a 6.4 by $11.1 \mathrm{~mm}$ cross-section duct. The two phases are measured in two successive runs made with and without a retro-reflector. In the direct backscatter configuration (i.e., without the retro-reflector) gas velocity measurements were made over a wide range of flow regimes, with bubbles as small as $0.75 \mathrm{~mm}$ in diameter, to slugs as large as $10 \mathrm{~mm}$ wide by $30 \mathrm{~mm}$ long. With the retro-reflector, the probe measured the liquid velocity by utilizing direct forward-scattered light to detect the seed particles following the liquid flow. The accuracy of the liquid measurements was shown to be a function of the data rate. The data rate in forward scatter due to seed particles should be at least 100 times greater than the data rate of the bubbles scattering light in the measurement volume. If this criterion is met, the liquid velocity can be $99 \%$ accurate. If this cannot be attained, then signal level discrimination can be used to eliminate large bubble signals for the forward-scattering measurements. 


\section{REFERENCES}

Adrian, R.J. 1983: Laser velocimetry. In: Fluid mechanics measurements. (ed. Goldstein, R.J.). Chap. 5, pp. 155-244. Washington: Hemisphere Pub1. Corp.

Boerner, T.; Martin, W.W.; Leutheusser, H.J. 1984: Comparative measurements in bubbly two-phase flow using laser-Doppler and hot-film velocimetry. Chem. Eng. Commun. 28, 29-43

Brankovic, A.; Currie, I.G.; Martin, W.W. 1984a: Laser-Doppler measurements of bubble dynamics. Phys. Fluids $27,348-355$

Brankovic, A.; Boerner, T.; Martin, W.W. 1984b: The measurement of mass transfer coefficients of bubbles rising in liquids using laser-Doppler anemometry. In: Laser anemometry in fluid mechanics. (eds, Adrian, R.J. et a1.). pp. 153-161. Lisbon: Ladoan-Instituto Superior Tecnico

Brankovic, A.; Mettrick, C.J.; Currie, I.G. 1986: Two-color LDA measurement of turbulent two-phase pipe flow. In: Proceedings of the third international symposium on applications of laser anemometry, to fluid mechanics. pp. 419-431. Lisbon: Ladoan-Instituto Superior Tecnico

DANTEC laser anemometry catalog 1983: Publ. No. 3205

Davies, W.E.R. 1973: Velocity measurements in bubbly two-phase flows using laser Doppler anemometry (Part I). UTIAS Tech. Note No. 184. University of Toronto

Davies, W.E.R.; Unger, J.I. 1973: Velocity measurements in bubbly twophase flows using laser Doppler anemometry (Part II). UTIAS Tech. Note No. 185. University of Toronto

Durst, F.; Zaré, M. 1975: Laser Doppler measurements in two-phase flows. In: Proceedings of the LDA symposium. pp. 403-429. Copenhagen

Durst, F.; Melling, A.; Whitelaw, J.H. 1976: Principles and practice of laser-Doppler anemometry. London: Academic Press

Durst, F.; Taylor, A.M.K.P; Whitelaw, J.H. 1984: Experimental and numerical investigation of bubble-driven laminar flow in an axisymmetric vessel. Int. J. Multiphase Flow 10, 557-569

Durst, F.; Schönung, B.; Selanger, K.; Winter, M. 1986: Bubble-driven liquid flows. J. Fluid Mech. 170, 53-82 
Grainer, N.; Höner, B.; Dialer, K. 1984: Influence of dispersed gas on the local structure of turbulent liquid flow. Ger. Chem. Eng. 7, 109-114

Jones, G.T.; Glasgow, L.A.; Erickson, L.E.; Patel, S.A.; Lee, C.H. 1990: Investigation of the use of laser-Doppler velocimetry in two-phase bubbly flows. Chem. Eng. Commun. 97, 181-196

Kvernvold, 0.; Vind y, V.; Shitvedt, T.; Saasen, A.; Selmer-01son, S. 1984: Velocity distribution in horizontal slug flow. Int. J. Multiphase Flow 10, 441-457

Lance, M.; Marié, J.L.; Bataille, J. 1985: Homogeneous turbulence in bubbly flows. In: Fundamental Aspects of Gas-Liquid Flows (ed.

Michaelidis, A.A.). FED Vol. 29, pp. 117-124. ASME

Lance, M.; Bataille, J. 1991: Turbulence in the liquid phase of a uniform bubbly air-water flow. J. Fluid Mech. 222, 95-118

Lee, S.L.; Cheng, Y.Z.; Yang, Z.H. 1988: An LDA gating technique for bubble measurement in dilute three-phase suspension flows. In: , Optical particle sizing: theory and practice (eds. Gouesbet, G. and Grehan, G.). pp. 455-463. New York: Plenum Press

Liska, J.J.; Martin, W.W.; Abdelmessih, A.H 1982: On measuring slip velocity of bubbles using laser doppler anemometry," In: Proceedings of the seventh international heat transfer conference. Vol. 5, pp. 243-247. Munich

Marié, J.L.; Charnay, G.; Bataille, J. 1982: Investigation of turbulence in two-phase dispersed flows using laser doppler anemometry. In: Proceedings of the international symposium on applications of laserdoppler anemometry to fluid mechanics. Lisbon

Marié, J.L. 1983: Investigation of two-phase bubbly flows using laser doppler anemometry. PhysicoChemical Hydrodynamics 4, 103-118

Marié, J.L.; Lance, M. 1984: Turbulence measurements in two-phase bubbly flows using laser doppler anemometry. In: Measuring techniques in gasliquid two phase flows. (eds. Delhaye, J.H. and Cognet, G.). pp. 141148. Berlin: Springer-Verlag

Martin, W.W.; Adbelmessih, A.H.; Liska, J.J.; Durst, F. 1981: Characteristics of laser-doppler signals from bubbles. Int. J. Multiphase Flow 7, 439-460 
Martin, W.W.; Chandler, G.M. 1982: The local measurement of the size and velocity of bubbles rising in liquids. App 1. Sci. Research 38, 239-246

Neti, S.; Colella, G.M. 1983: Development of a fiber optic doppler anemometer for bubbly two-phase flows. EPRI Report NP-2802

Ohba, K.; Kishimoto, I.; Ogasawara, M. 1976: Simultaneous measurement of local liquid velocity and void fraction in bubbly flows using a gas laser - Part I: Principle and measuring procedure. Tech. Reports of the Osaka Univ. 26, 547-556

Ohba, K.; Kishimoto, I.; Ogasawara, M. 1977a: Simultaneous measurement of local liquid velocity and void fraction in bubbly flows using a gas laser - Part II: Local properties of turbulent bubbly flows. Tech. Reports of the Osaka Univ. 27, 229-238

Ohba, K.; Kishimoto, I.: Ogasawara, M. 1977b: Simultaneous measurement of local liquid velocity and void fraction in bubbly flows using a gas laser - Part III: Accuracy of measurement. Tech. Reports of the Osaka Univ. 27, 475-483

Ohba, K.; Tsutomu, Y.; Matsuyama, H. 1986: Simultaneous measurements of bubble and liquid velocities in two-phase flow using laser doppler velocimeter. Bulletin of JSME 29, 2487-2493

Sullivan, J.P.; Theofanous, T.G 1979: The use of LOV in two-phase bubbly pipe flow. In: Laser velocimetry and particle sizing. (eds. Thompson, H.D. and Stevenson, W.H.). pp. 391-394. Washington: Hemisphere Publ. Corp.

Sheng, Y.Y.; Irons, G.A. 1991: A combined laser doppler anemometry and electrical probe diagnostic for bubbly two-phase flow. Int. J. Multiphase Flow $17,585-598$

Sun, T.-Y.; Parthasarthy, R.; Faeth, G.M. 1985: Structure of bubbly round condensing jets. In: Multiphase flow and heat transfer. (eds. Dhir, V.K. et al.). HTD Vol. 47, pp. 75-84. ASME

Sun, T.-Y.; Faeth, G.M. 1986a: Structure of turbulent bubbly jets - I. Methods and centerline properties. Int. J. Multiphase Flow 12, 99-114

Sun, T.-Y.; Faeth, G.M. 1986b: Structure of turbulent bubbly jets - II. Phase property profiles. Int. J. Multiphase Flow 12, 115-126

Theofanous, T.G.; Sullivan, J. 1982: Turbulence in two-phase dispersed flows. J. Fluid Mech. 116, 343-362 
Wilson, M.L. 1982: Investigation of two-phase flow details using laser doppler velocimetry. TSI Quarterly 8, 3-8

Wolf, J.R.; Larson, T.K.; Wilson, M.L. 1983: Measurement of two-phase flow velocity using a laser doppler anemometer. In: Instrumentation in the Aerospace Industry, Vol. 29, pp. 23-34. Triangle Park, NC; ISA.

Yang, Z. H.; Lee, S.L. 1991: Measurement of large air bubbles and solid particles moving in the three-phase suspension flow using laser-doppler anemometry. In: Multiphase flow and heat transfer -Second international symposium, Vol. 2. (eds. Chen, X.-J. et al.). pp. 1371-1379. New York: Hemisphere Publ. Corp.

Zuber, N.; Findlay, J.A. 1965: Average volumetric concentration in twophase flow systems. ASME J. Heat Transfer 87, 453-468 
Table 1. Summary of Selected Studies: LDV Measurements in Gas-Liquid Two-Phase Flows(1)

\begin{tabular}{|c|c|c|c|c|c|c|}
\hline Publication(a) & $\begin{array}{c}\text { IDV } \\
\text { Conelgaration(2) }\end{array}$ & Type of Plow & $\begin{array}{l}\text { Teact Soction } \\
\text { Goometry }\end{array}$ & $\begin{array}{l}\text { Mar. } \\
\text { Void } \\
\text { Prection }\end{array}$ & Docilired(3) & Comente \\
\hline $\begin{array}{l}\text { Davie: (1973); } \\
\text { Davieas and (linger } \\
\text { (1973) }\end{array}$ & $\begin{array}{l}\text { detectors at } 180 \\
\text { deg; ond either } 3.4 \\
\text { or } 7.5 \text { deg. }\end{array}$ & $\begin{array}{l}\text { vertical stean/uater and } \\
\text { air/water pipe tlows }\end{array}$ & $\begin{array}{l}10.7 \text { m mipe } \\
\text { dianeler pipe }\end{array}$ & $50 x$ & $\mathrm{~V}_{\alpha} \mathrm{V}_{1}$ & 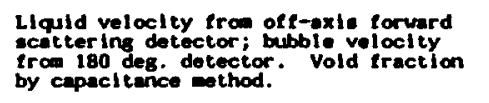 \\
\hline $\begin{array}{l}\text { Ohbe ot il: } \\
\text { (1976; 1977a; } \\
1977 \mathrm{~b})\end{array}$ & $\begin{array}{l}\text { single detector at } 0 \\
\text { deg. }\end{array}$ & $\begin{array}{l}\text { vertical air/water pipe } \\
\text { flow }\end{array}$ & epprox. 11 m. & 308 & $\begin{array}{l}\mathrm{V}_{1} \mathrm{~V}_{1}^{\prime} \\
\alpha\end{array}$ & $\begin{array}{l}\text { Line average vold fruction by laser } \\
\text { light atteriution. }\end{array}$ \\
\hline $\begin{array}{l}\text { Sullivan and } \\
\text { Theofanous } \\
\text { (1979); } \\
\text { Theof anoug and } \\
\text { Sul11 van (1982) }\end{array}$ & $\begin{array}{l}\text { Ingle detector at } \\
180 \text { deg. }\end{array}$ & $\begin{array}{l}\text { vertlcal nitrogen/water } \\
\text { pipe flow }\end{array}$ & $\begin{array}{l}57.0 \mathrm{~mm} \\
\text { diamecer pipe }\end{array}$ & & $V_{1} V_{1}^{\prime}$ & $\begin{array}{l}\text { Appllevde digcr laminacton ised to } \\
\text { of iminate bubble signels. }\end{array}$ \\
\hline $\begin{array}{l}\text { W11 } \operatorname{son}(1981 ; \\
\text { Nole ec } 192) ;(1983)\end{array}$ & $\begin{array}{l}\text { eingle detector at } 0 \\
\text { deg. }\end{array}$ & $\begin{array}{l}\text { vertical air/water and } \\
\text { stem/water pipe flows }\end{array}$ & 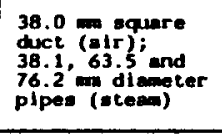 & 87.28 & $\begin{array}{l}\text { velocity } \\
\text { probablitity } \\
\text { density }\end{array}$ & 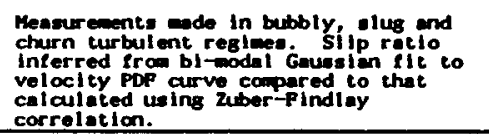 \\
\hline 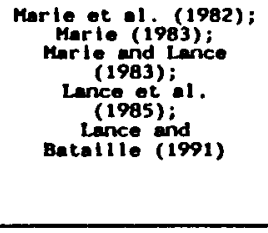 & $\begin{array}{l}\text { eingle dotector at } \\
\text { io deg. }\end{array}$ & $\begin{array}{l}\text { vertical =1r/water pipe } \\
\text { elow }\end{array}$ & $\begin{array}{l}450 \mathrm{~mm} \text { mquare } \\
\text { duct }\end{array}$ & 78 & 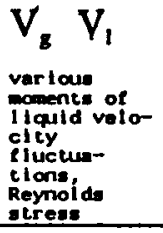 & 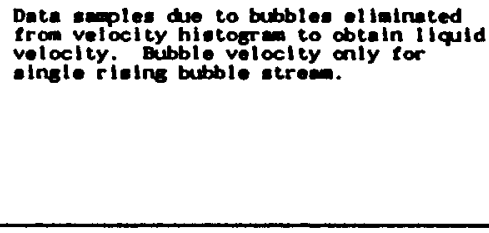 \\
\hline $\begin{array}{l}\text { Hotl end Colelle } \\
(1983)\end{array}$ & $\begin{array}{l}\text { detectors at } 0 \text { and } \\
180 \text { deg. }\end{array}$ & $\begin{array}{l}\text { vertical air/uater pipo } \\
\text { ilow }\end{array}$ & $28.0 \mathrm{mon}$ pipo & $\begin{array}{l}\max ^{\max } \mathrm{ilt} \\
8 \times 10^{\prime}\end{array}$ & $V_{V_{1}} V_{1}$ & 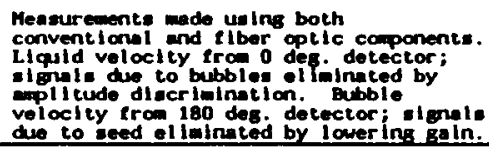 \\
\hline$\underset{(1984)}{\text { Boerner et al }}$ & $\begin{array}{l}\text { eingle detector at } 0 \\
\text { deg. }\end{array}$ & $\begin{array}{l}\text { sir bubbles rising in water } \\
\text { (4 to } 16 \text { atroand })\end{array}$ & $\begin{array}{l}120 \text { oby } \\
\text { variable } \\
\text { vidth of } 9.5 \text { to } \\
120 \text { min }\end{array}$ & $23 x$ & $\begin{array}{l}\mathrm{V}_{1} \mathrm{~V}_{1}^{\prime} \\
\alpha\end{array}$ & 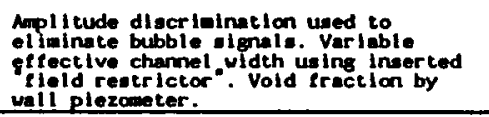 \\
\hline Grainer ot $\underset{(1984)}{ }=1$ & $\begin{array}{l}\text { eingle detector at o } \\
\text { deg. }\end{array}$ & $\begin{array}{l}\text { al jet dlecherged into } \\
\text { vertical vater pipe tlow }\end{array}$ & $\begin{array}{l}1.5 \mathrm{~m} \text { nozzle in } \\
100=\text { squere } \\
\text { duct }\end{array}$ & $20 \pi$ & $V_{1} V_{1}^{\prime}$ & 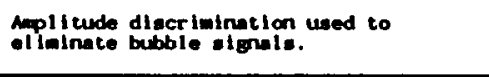 \\
\hline
\end{tabular}

否 
Table 1 (Continued)

\begin{tabular}{|c|c|c|c|c|c|c|}
\hline${ }_{(1984)}^{\text {Rvernold }}=1$. & $\begin{array}{l}\text { Ingle detector at O } \\
\text { deg. }\end{array}$ & 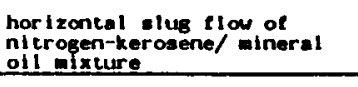 & $\begin{array}{l}24.0 \text { mo } \\
\text { dinmeter pipe }\end{array}$ & & $V_{1}$ & 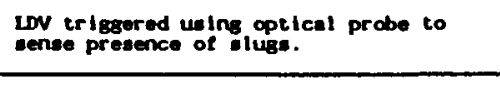 \\
\hline $\operatorname{saltman~} e t_{(1984)}=1$ & $\begin{array}{l}\text { three oft-axis } \\
\text { forward gactier ing } \\
\text { detectors }\end{array}$ & $\begin{array}{l}\text { eir/water jet and bubbly } \\
\text { ilow around: athip } \\
\text { propeller }\end{array}$ & & & $V_{g} d_{b}$ & 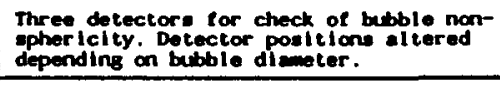 \\
\hline 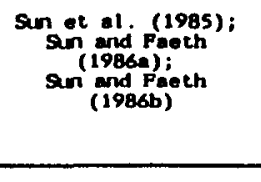 & $\begin{array}{l}\text { Ingle detector at } 0 \\
\text { or } 45 \text { deg. }\end{array}$ & 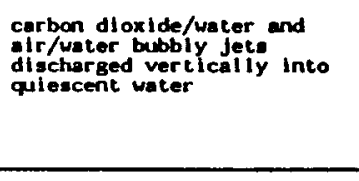 & 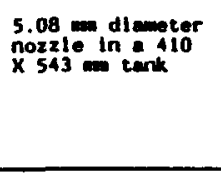 & 108 & $\begin{array}{l}\mathrm{V}_{\mathrm{g}} \mathrm{V}_{\mathrm{g}}^{\prime} \\
\mathrm{V}_{1} \mathrm{~V}_{1}^{\prime} \\
\text { Reynoldz } \\
\text { strease }\end{array}$ & 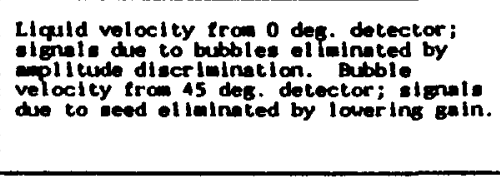 \\
\hline 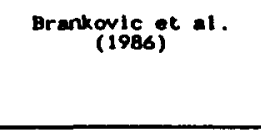 & 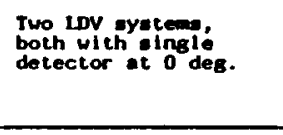 & 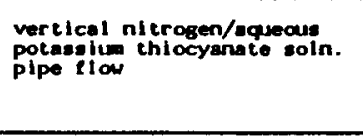 & 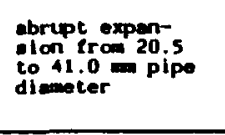 & 18 & $\begin{array}{l}V_{g} d_{b} \\
V_{1} \\
V_{i}^{\prime}\end{array}$ & 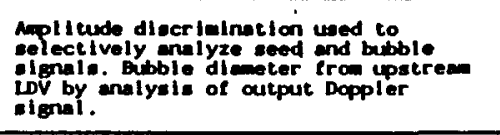 \\
\hline Othas of $A 1 . \quad(1986)$ & $\begin{array}{l}\text { detectors at } 0 \text { and } \\
90 \text { deg. }\end{array}$ & $\begin{array}{l}\text { Yertical alr/water plpo } \\
\text { ilow }\end{array}$ & $\begin{array}{l}11.5-\text { dact } \\
\text { square dxce }\end{array}$ & 30.8x & $V_{g} V_{1}$ & 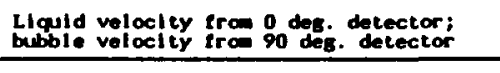 \\
\hline 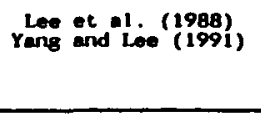 & 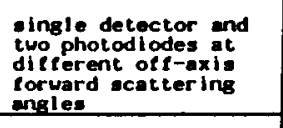 & 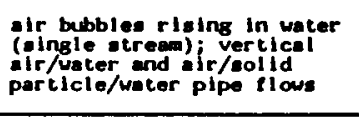 & 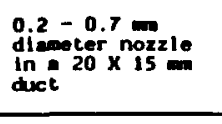 & & $V_{g} d_{b}$ & 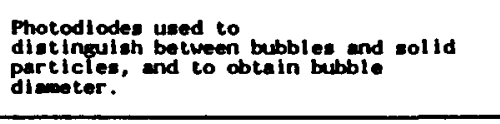 \\
\hline Jones et al. (1990) & $\begin{array}{l}\text { Ingle dotector at } \\
\text { iBo deg. }\end{array}$ & 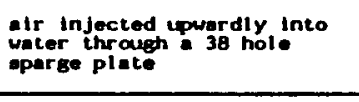 & 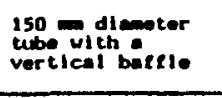 & 168 & $V_{1}$ & 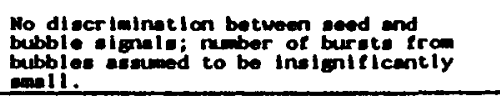 \\
\hline Shengs, end trons & $\begin{array}{l}\text { ingle decectar at } 0 \\
\text { or } 180 \text { deg. }\end{array}$ & 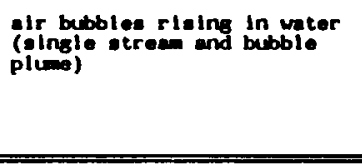 & $\begin{array}{l}100 \text { Fo square } \\
\text { and } 500 \text { diemeter }\end{array}$ & 508 & $\begin{array}{l}V_{B} V_{1} \\
d_{b} \alpha\end{array}$ & 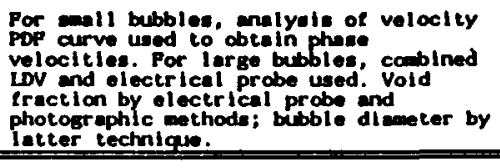 \\
\hline
\end{tabular}

notes: (1) A blank cell indicates information was not provided by author(s).

(2) 0 deg. corresponds to direct forward scattering, 180 deg. to direct back scattering.

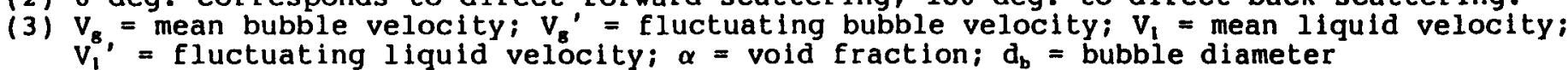




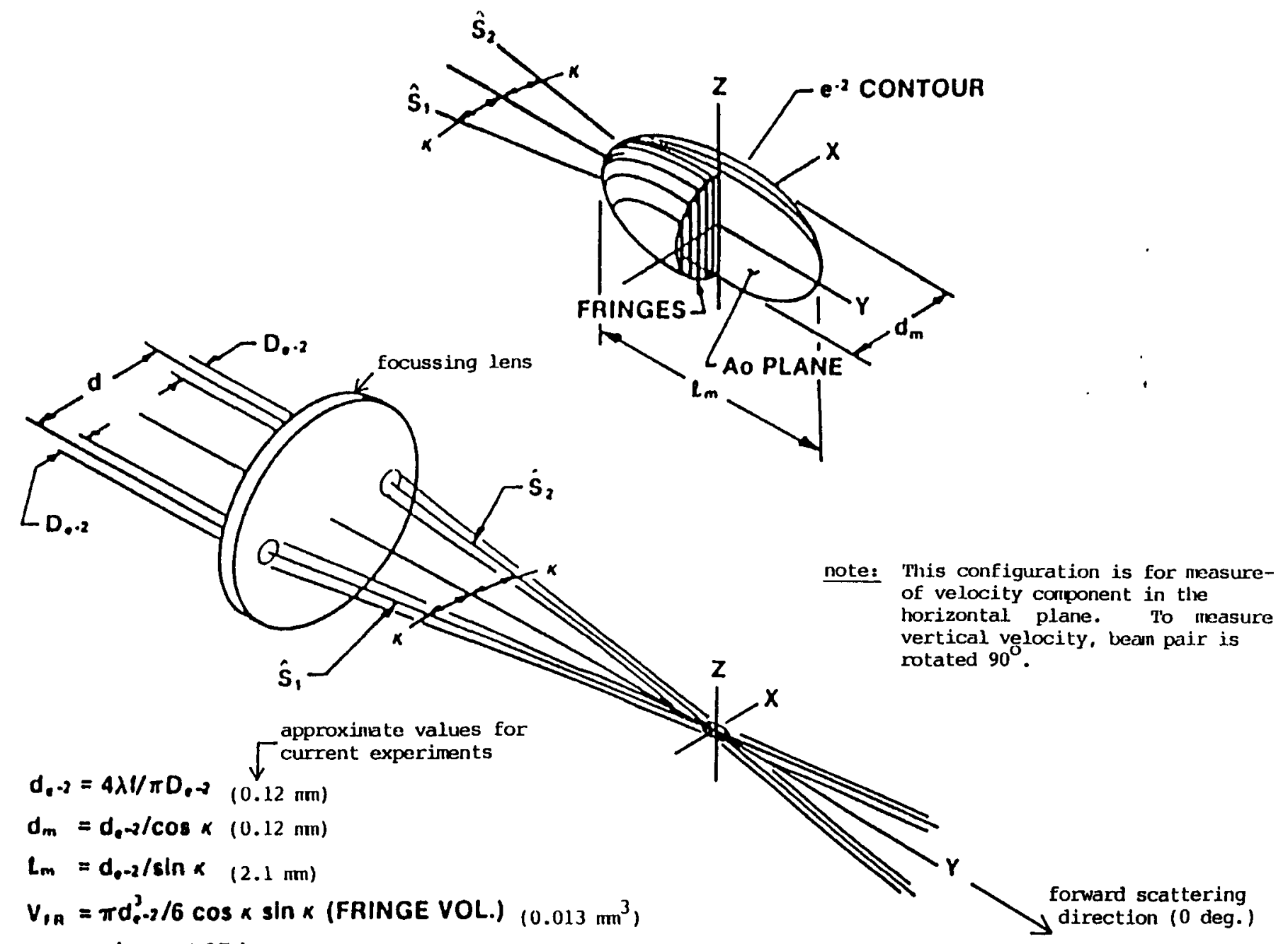

$N_{\text {FR }}=\frac{d_{m}}{d_{1}}=\frac{1.27 \mathrm{~d}}{D_{0.2}}$ (NO. OF FRINGES) (39) 


\section{Figure 2}

\section{Retro-Reflector and Lens with Standard LDV Probe}

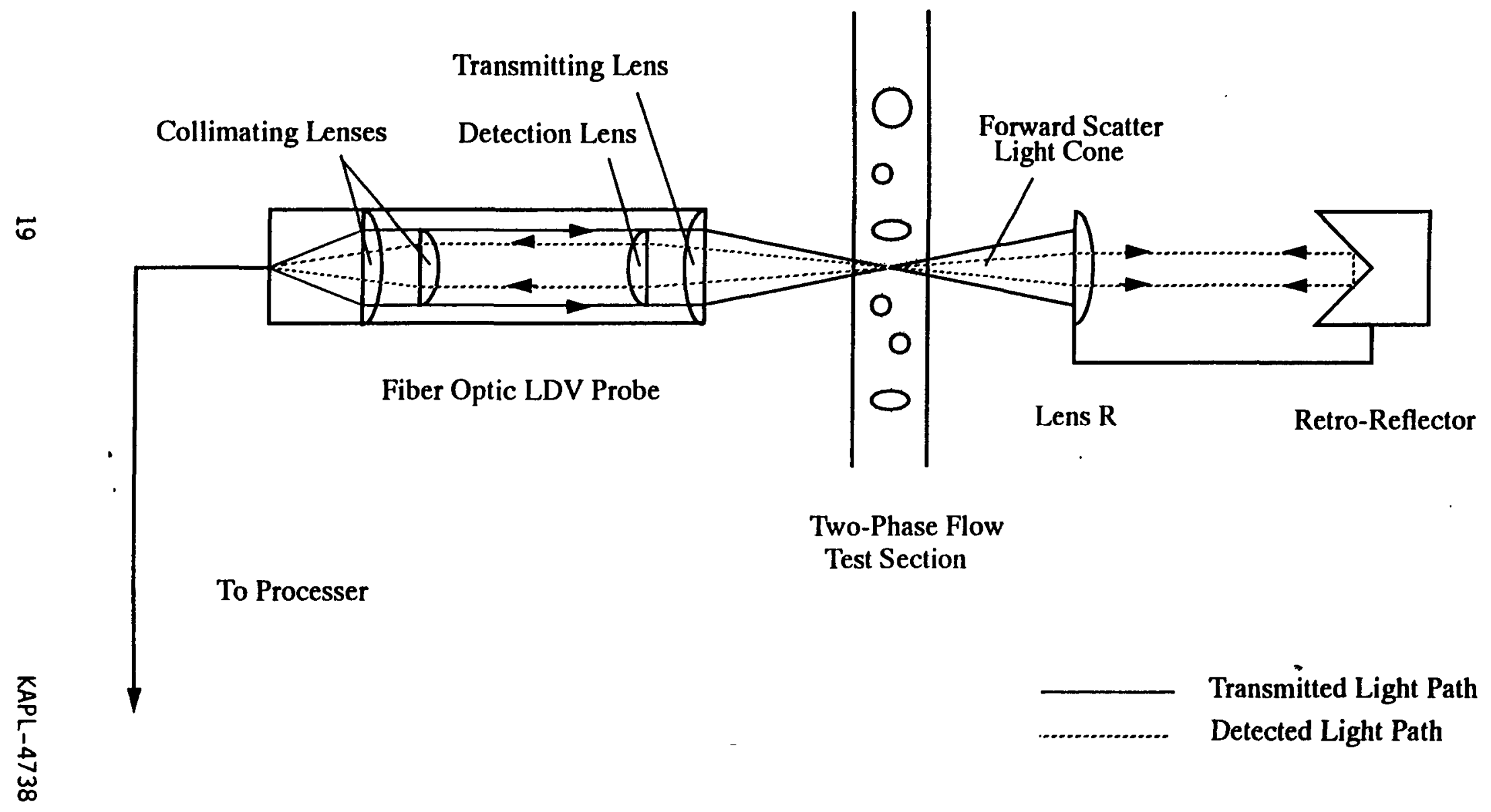


Figure 3

Experimental Set-Up

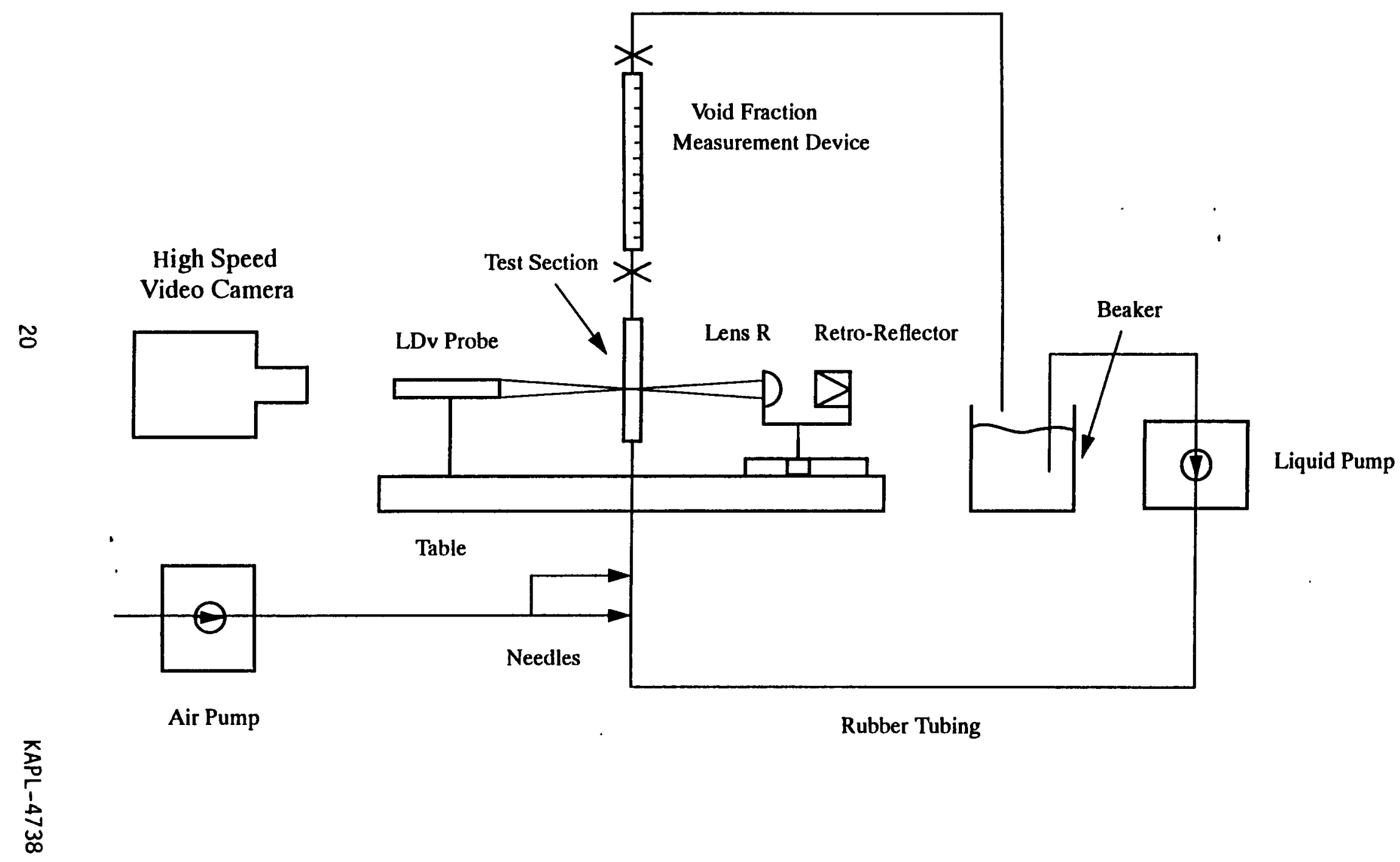


Figure 4

Bubble Velocity Comparison, No Liquid Flow

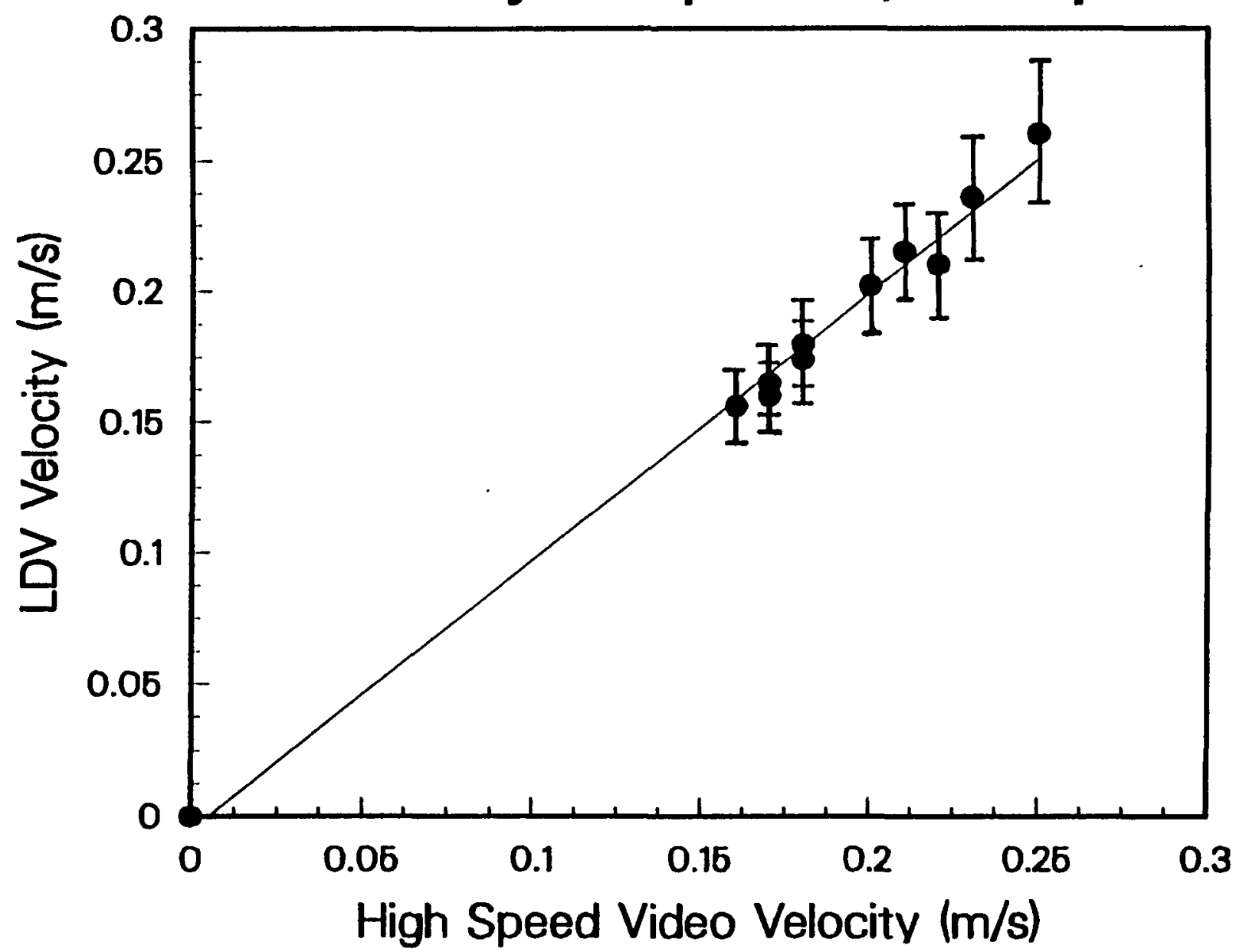

$\underset{\infty}{\text { 중 }}$ 
Figure 5

Liquid Velocity Proflles, No Gas Flow

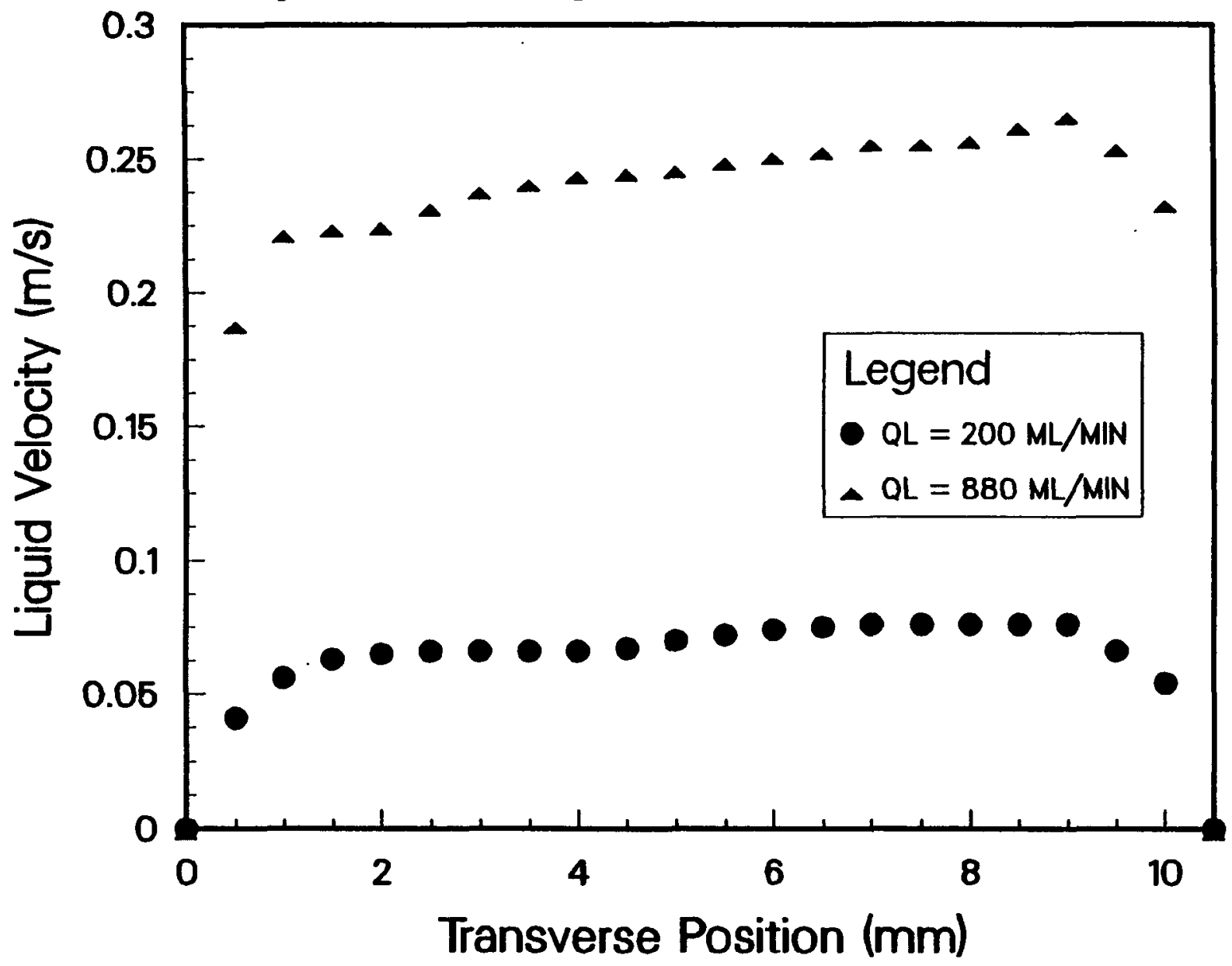


Figure 6

\section{Data Rate Response at Constant Gain}

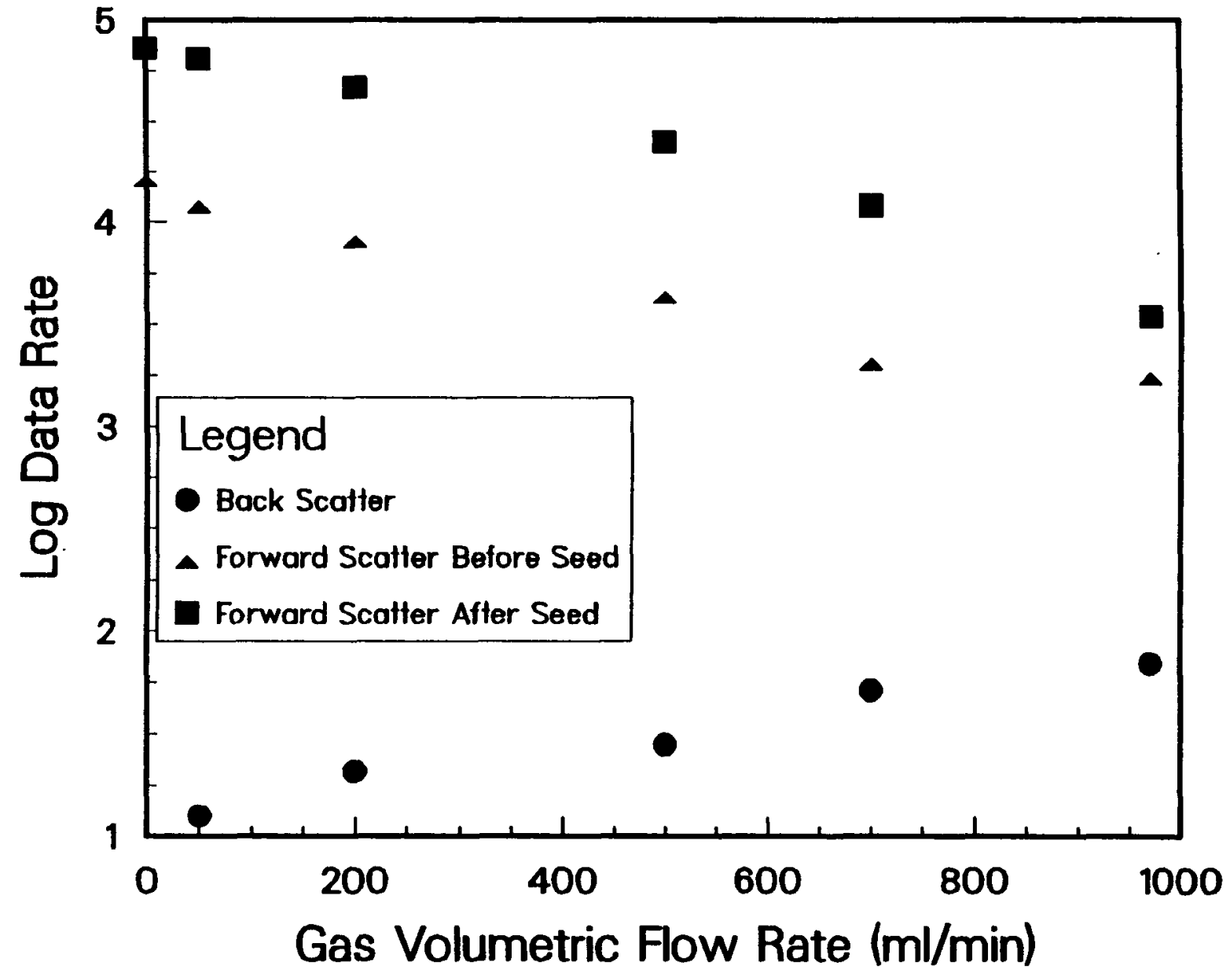


Figure 7

Two-Phase Velocity Measurements,No Liquid Flow

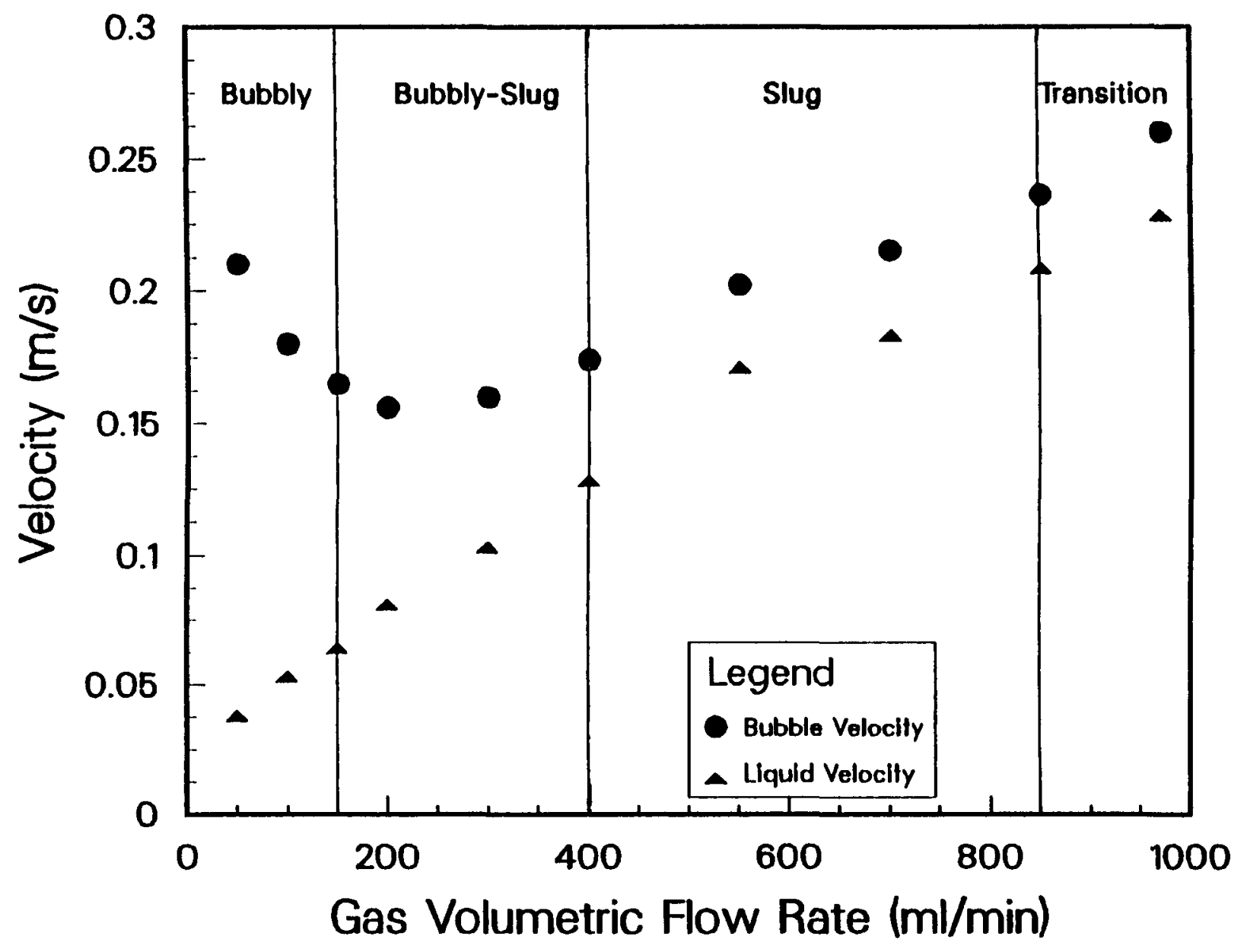


Figure 8

Two-Phase Velocity Measurements, $Q \mathbf{l}=300 \mathrm{ml} / \mathrm{min}$

जั

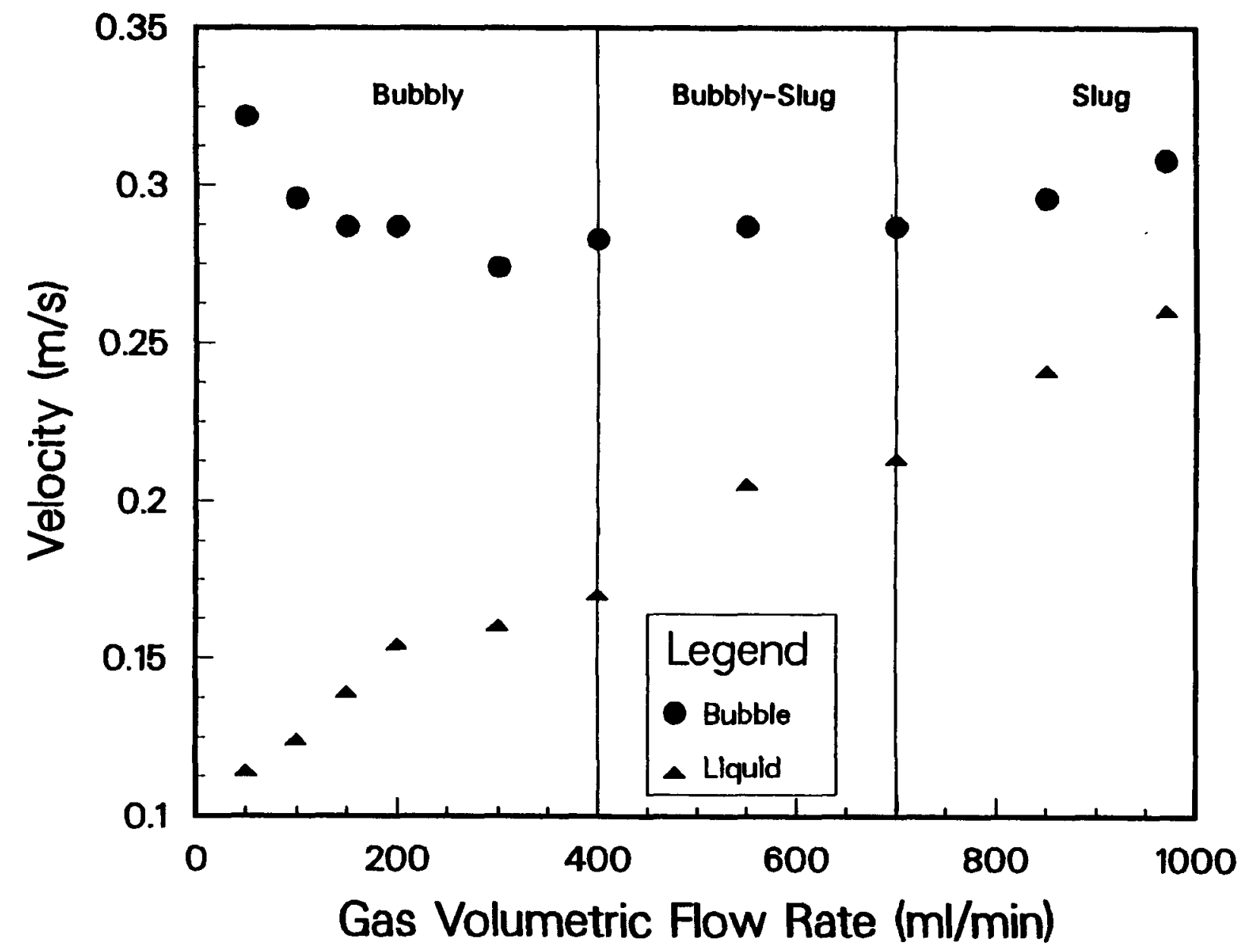

碚 
Figure 9

Two-Phase Velocity Measurements, QL $=600 \mathrm{ML} / \mathrm{MIN}$

๙

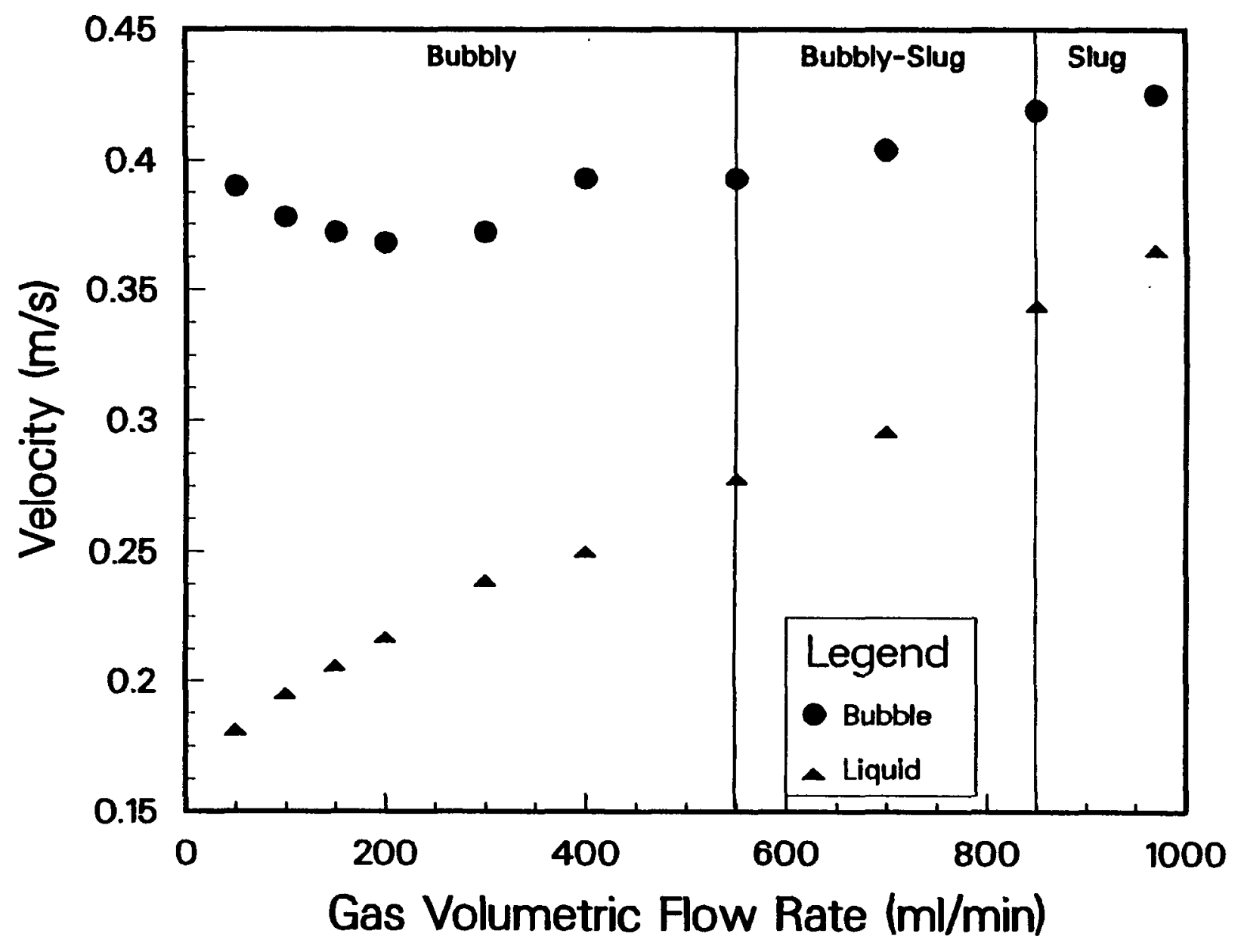

㫘 
Figure 10

Two-Phase Velocity Measurements, $\mathrm{QI}=900 \mathrm{ml} / \mathrm{min}$

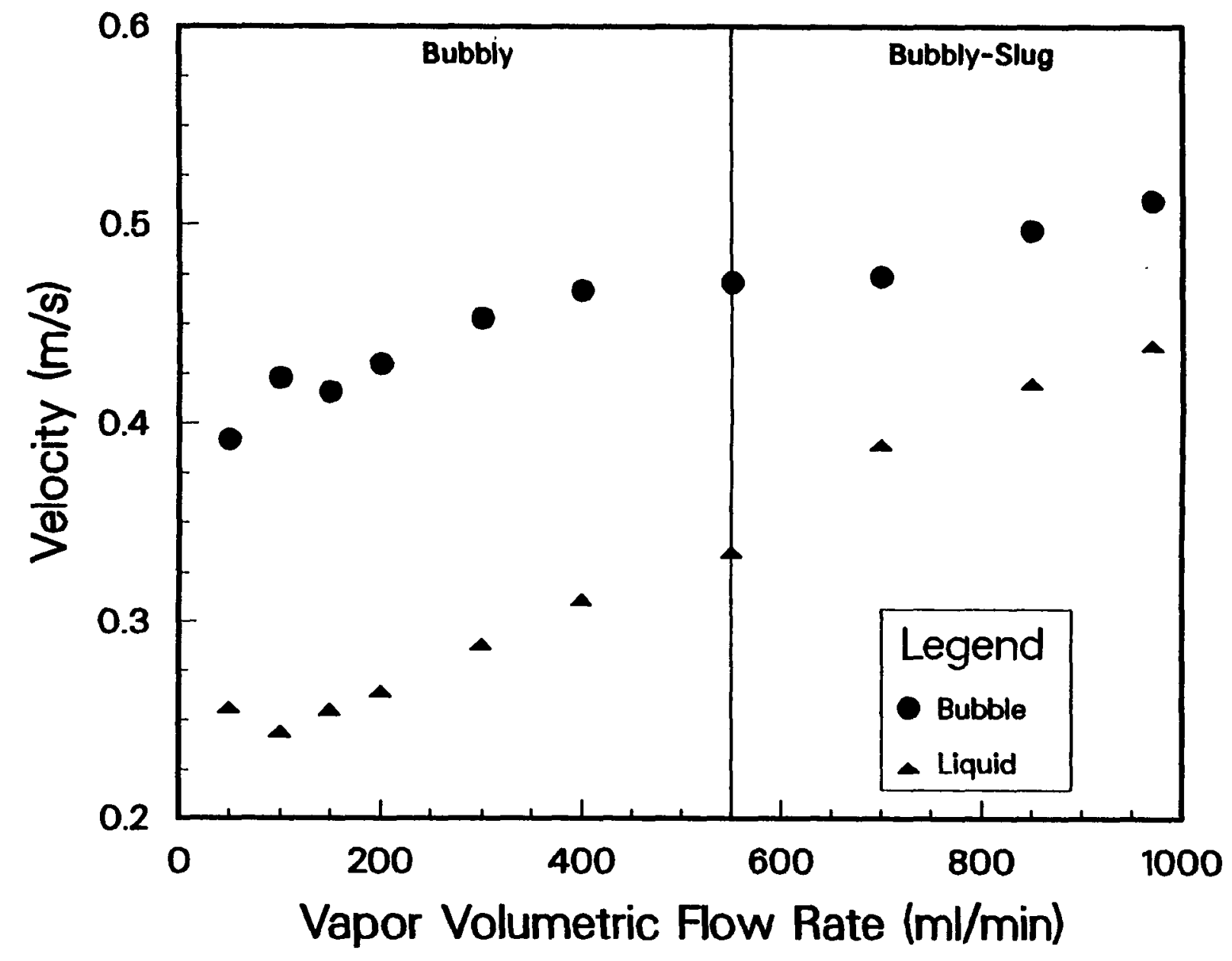


Figure 11

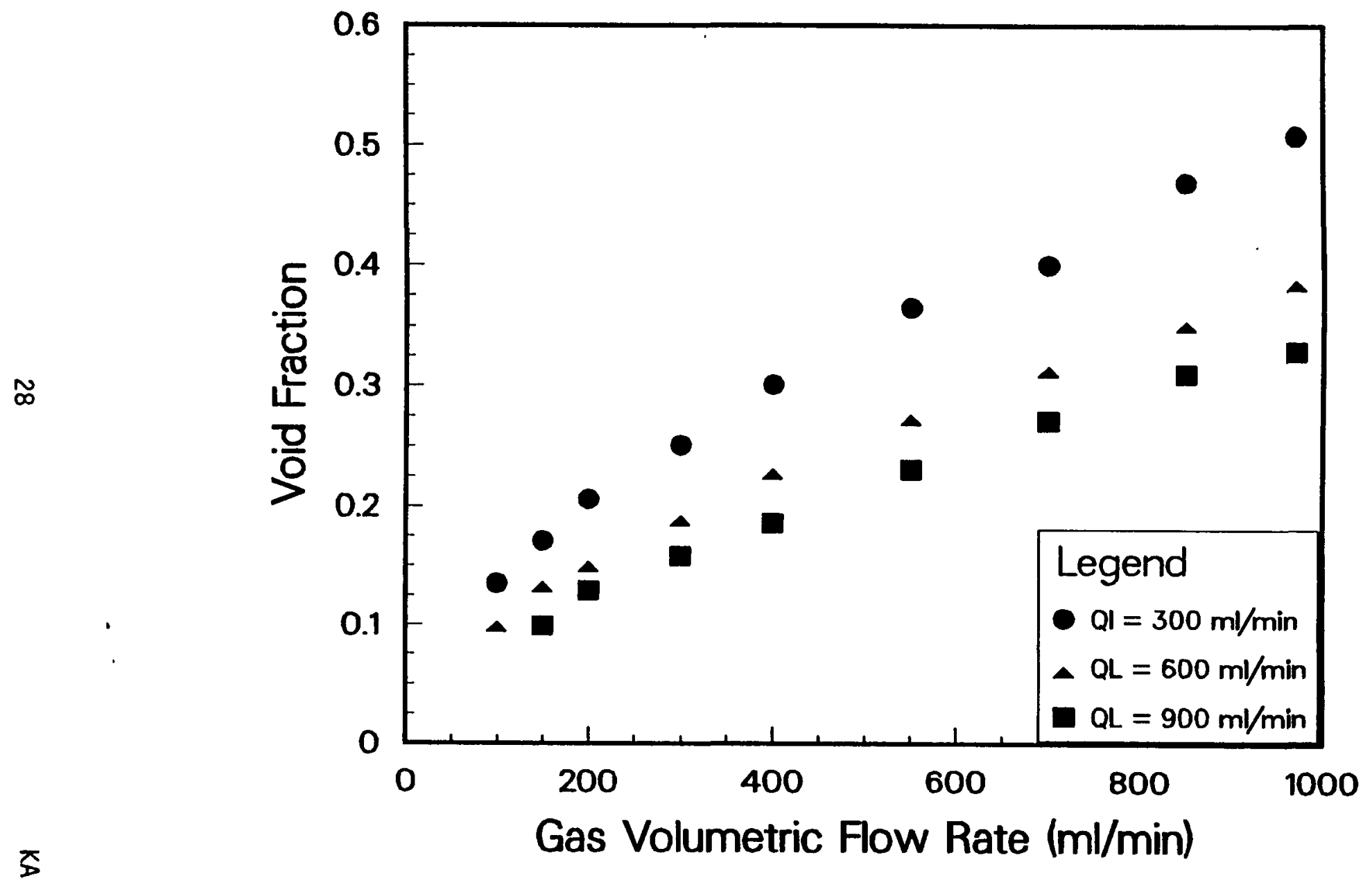




\section{Plate 1 - Two-Phase Flow Regimes for $Q_{1}=0 \mathrm{ml} / \mathrm{min}$}

$\tilde{ช}$

(a)

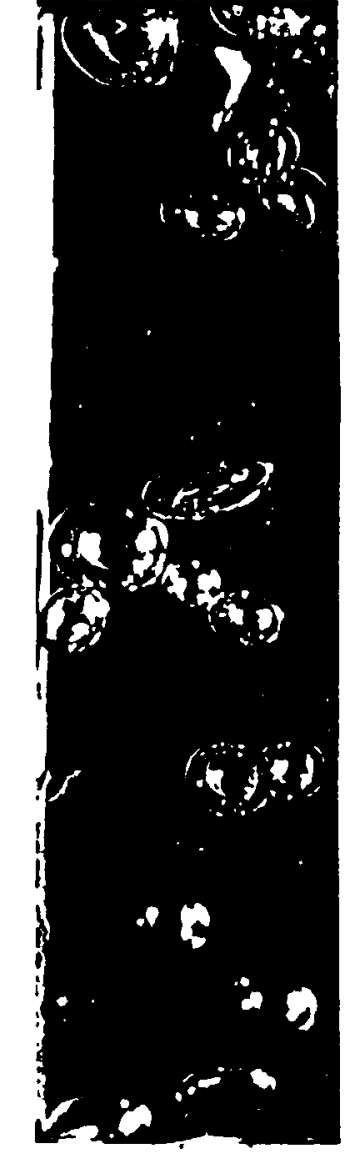

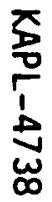
Bubbly (b)

$$
\mathrm{Q}_{\mathrm{g}}=50 \mathrm{ml} / \mathrm{min}
$$
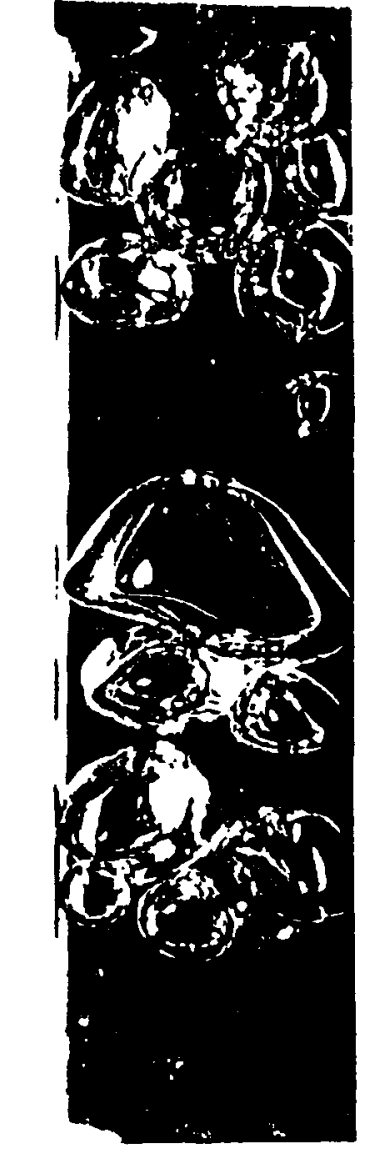

(c)

$Q_{\mathrm{g}}=350 \mathrm{ml} / \mathrm{min}$ Bubbly/Slug

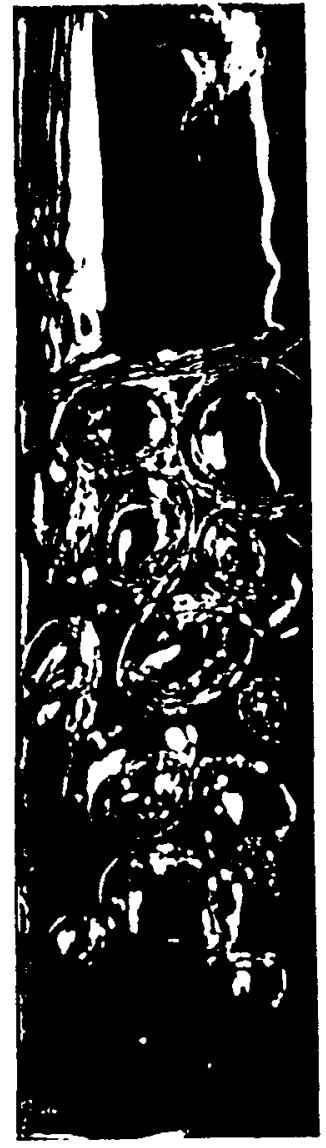
$Q_{g}=600 \mathrm{ml} / \mathrm{min}$ Slug

(d)

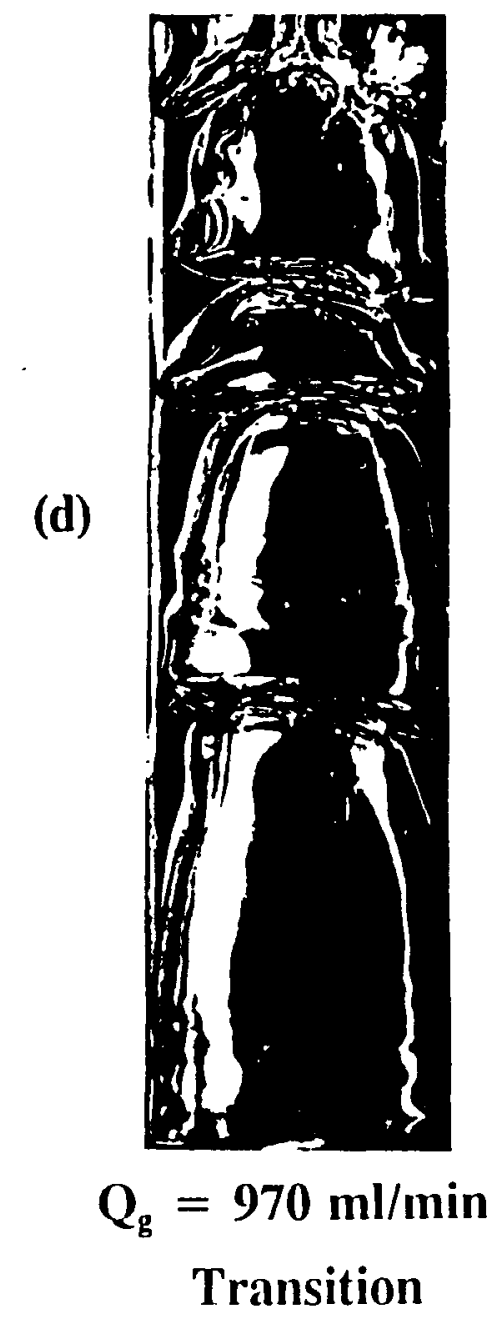

